\title{
Social Media in EFL Context: Attitudes of Saudi Learners
}

\author{
S. M. Fazlul Haque \\ Dept of English, College of Languages, Najran University, KSA \\ Norah Mofareh Al Salem \\ Dept of English, College of Languages, Najran University, KSA
}

\begin{abstract}
This study investigates the impact of Social Media (SM) on students' attitudes towards the process of learning EFL from the learners' perspectives. The hypothesised model is developed through social learning theory proposed by Vygotsky (1978). The sample population of this research consists of 228 undergraduate students (153 females and 75 males) enrolled in the Department of English Language at Najran University in Saudi Arabia. The instruments used to gather data from the participants included a self-designed online electronic survey and semi-structured interviews. Results show that Najran University students believe that SM positively improves their understanding of English. Moreover, students agree that SM is a good platform to improve their proficiency in English. They also reported that SM changes their attitudes towards English positively. The findings also indicate that SM is a good platform for students as it provides opportunities for learners to study foreign languages. As SM tools grow and new generations get attached to them, additional studies on the adoption of these tools must be conducted to support students' learning.
\end{abstract}

Index Terms — social media, learners' attitudes, Saudi University students, EFL

\section{INTRODUCTION}

In contemporary society, technological advancement has had a tremendous impact on the younger generations to the point that it has become an integral part of their lives. The adoption of new technology has played a critical role in the provision of various platforms for people not only to interact but also to learn, share knowledge, exchange information and express their thoughts and ideas. Web 2.0 technologies are important for the present generation, whose members have become digital natives. Prensky (2006) stated, 'Our students are no longer little versions of us as they may have been in the past. In fact, they are so different from us that we can no longer use either our 20th century knowledge or our training as a guide to what is best for them educationally. Our students, as digital natives, will continue to evolve and change so rapidly that we will not be able to keep up' (p. 9). Prensky (2006) also stated that instructors who still use pre-digital language are struggling in the sense that they cannot continue using the old language in teaching a generation who speak an entirely new language.

Considering the interaction through web-based tools and mobile applications, such as blogs, wikis, podcasts, video casts, Facebook, online forums and microblogging sites like Twitter, students in non-English speaking countries have changed their attitudes towards learning English as a foreign language (EFL) (Bahrani, 2011). These learners can socialise with native speakers of English and others who have developed proficiency in English as a second language (ESL). In comparison to the classroom setting that limits the level of interaction among students, social media (SM) provides various platforms that enable learners to interact with a wide audience. They can create content and share it within these virtual, digital communities. Students can participate in group discussions as well as share resources and information with one another. Globally, several non-English speaking countries have adopted comprehensive language learning programmes that allow students to learn ESL. Allam and Elyas (2016) found that several factors have influenced the need to acquire proficiency in English. For example, the English language has become a lingua franca; thus, almost every aspect of socio-political and economic aspects of the society uses it. Therefore, having knowledge of English is a prerequisite for working and interacting with people all over the world. Many statistical reports prove the domination of English language on the Internet in general and social media in particular. In fact, the well-known world wide web technology surveys (W3Techs) published a report that 51.9\% of Internet content is in English, which is the most frequently used language in 2018.

Moreover, knowledge of the English language is associated with high education and social status. However, specialising in English as a major to learn the language is unnecessary because people who are eager to learn succeed in any circumstances. Fortunately, learning English has become easier due to the emergence of SM. This research examines the impact of SM platforms on students' attitudes towards EFL, in which interaction in SM can influence students to acquire positive or negative attitudes towards learning EFL.

\section{A. SM and Its Impact on Students' Attitudes}


The geographical distance that separates different cultures has become closer in recent years, thus increasing interactivity and socialisation among people of different cultures. Adopting web-based telecommunication tools, such as the Web 2.0, has contributed to the tremendous improvement in the interaction between students in English and nonEnglish speaking countries (Seo, 2013). Creating various platforms, such as online discussion groups, Facebook, Twitter and podcasts, allows learners to have different venues where they can observe and learn the critical aspects surrounding the English language.

Due to the tremendous increase in the usage of social network sites (SNSs), such as Twitter, Facebook and blogs, technology experts should develop advanced technologies to boost online interaction especially designed for learning purposes. Students who use SNSs only for pleasure should also recognise the importance of SM in the elaboration of their language in particular and their knowledge in general. Learners should fully grasp the usage of professional online platforms that can result in critical discussions, thereby boosting their proficiency and competency in EFL.

\section{B. Purpose of the Study}

The study evaluates the impact of SM on students' attitudes towards the process of learning EFL from its learners' perspectives. With the increasing use of online communication tools, such as blogs, Facebook and wikis around the world, determining the possible role that SM plays in influencing the attitudes of English learners in non-English speaking countries has become an important research endeavour (Yagci, 2014). Therefore, the study aims to determine how the constant use of SM for interaction affects EFL students' perception of English language. Given that attitudes can change in the short and long terms, the study focuses on EFL students in the Department of English at Najran University. Specifically, the study unravels how the use of web-based communication tools affects the perceptions of some Najran University students who are EFL learners.

Gender is significantly considered in the survey because it is an essential factor in the Saudi Arabian educational and socioeconomic landscape. Gender can influence students' attitudes towards SM use and, consequently, their academic performance. Therefore, this research explores the propensities of male and female students towards SM and how it can improve their English language proficiency.

Moreover, the study focuses on the extent to which respondents consider SM as a means of free and comfortable communication with their group members, especially those who lack confidence in face-to-face interaction and are shy. In addition to the perspective that SNSs provide channels for new kinds of information from the newsfeed, these channels should lessen the reluctance behind the active participation in discussions carried out in English. The study tried to answer the following questions:

1. How does SM improve students' understanding of English from the perspective of the EFL learners?

2. How does SM affect the students' proficiency in English from the perspective of the EFL learners?

3. How does SM usage influence the attitudes of EFL learners towards English?

4. Is there any statistically significant difference that can be attributed to gender and grade point average (GPA) in the attitudes of participants towards learning English through SM?

\section{LITERATURE REVIEW}

This research investigates the impact of SM on the attitudes towards English from the perspective of EFL learners. Therefore, two areas must be investigated: SM and learners' attitudes. Many forms of technology have been used in the field of education. One of these forms is Web 2.0, originally developed from Web 1.0. The term 'Web 2.0' was first introduced by O'Reilly (2005) when software developers started utilising the world wide web. Web 1.0 generally includes authentic materials, texts, pictures, audios, videos, webpages, discussion forums, emails, chatrooms, photos, music and videos. Web 2.0 refers to live materials, Flickr, podcasts, videocasts, blogs, wikis, online discussion boards and SNSs (Alm, 2006; Shih, 2011). Donelan, Kear and Ramage (2010) define Web 2.0 as a shift from static content to a dynamic platform based on collaboration. Web 2.0 technologies offer structures that can be used in learning environments, and their application offers new channels for learners to receive and exchange informative and constructive feedback from peers and instructors. Web 2.0 technologies include wikis, blogs, media-sharing services, SNSs, collaborative editing tools and modification technologies (O'Reilly, 2007; Donelan et al., 2010). Fralinger and Ownes (2009) found that learning through Web 2.0 applications has transformed the present learning industry.

Pedagogy, technology and social interaction are the key factors for a technology-enhanced learning environment. Thus, blended learning that combines Web 2.0 technologies and online peer assessment with face-to-face instruction has become a new and feasible strategy for instructors and students to enhance their performance and satisfaction (Shih, 2011).

Within an educational setting, information and communication technologies (ICTs) have stimulated new pedagogical practices that redefine the predictable methods of learning and teaching. SM platforms are the new formats of these novel technologies. Such platforms have been viewed as an active force among teachers, learners and information professionals. Kaplan and Haenlin (2010) defined social media as 'a group of Internet-based applications that build on the ideological and technological foundations of Web 2.0 and that allow the creation and exchange of user-generated content. It is a medium for social interaction as a super-set beyond social communication enabled by ubiquitously accessible and scalable communication techniques' (p. 63). SM platforms support collaboration, provide significant 
information sources and offer a venue of active engagement among participants and communication. These tools transform learners into active content creators from passive receivers of information. The term 'social networking' and 'social media' present similar issues and are often interchangeably used, but without a clear definition of either term. In general, the term 'social media' is most often used as a broad umbrella that includes many Web 2.0 functions, including social networking. 'Social media' is generally appropriate to define methods of conveying messages as an extension of traditional media outlets. Kaplan and Haenlin (2010) classified SM into six forms: projects produced collaboratively by users (e.g. Wikipedia), SNSs (e.g. Facebook), content communities (e.g. YouTube), blogs and microblogs (e.g. Twitter), virtual social worlds (e.g. Second Life), and virtual game worlds (e.g. World of Warcraft). Therefore, SM is a broad term that contains SNSs.

Baird and Fisher (2005) conducted the first major examination of potential uses of SM in education. They identified key advantages that SM platforms provide to today's neo-millennial learners. Their study readily points out that students these days have been raised in a world of interactive media, the Internet and digital messaging technologies. Therefore, they have different expectations and learning styles compared with previous generations. Elsayed (2011) said, 'As in today's environment, students have all day access to the library, varied information and social networking tools available via the Internet' (p. 6). This net-centric generation values their ability to use the web to create a self-paced, customised, on-demand learning path that includes multiple forms of interactive, social and self-publishing media tools (Goel \& Singh, 2016). Teachers who want to utilise SM in their academic courses to promote student learning should be prepared to support students and be active participants in the collaborative learning community. Dabbagh and Kitsantas (2012) stated, 'higher education institutions still primarily rely on traditional platforms such as course and learning management system that do not capitalise on the pedagogical affordances of social media' (p.3).

Al-Sharqi, Hashim and Kutbi (2015) evaluated the similarities and differences between art and science university students concerning their perceptions of the effect of SM on behaviour. The research involved 2,605 male and female participants of different ages, but all of them were college students. Their results indicated that art students are more immersed in and familiar with SM use than science students. The study further showed that learners benefit from the use of networking platforms. For art students, being online provides them with a channel to express their ideas, whereas, for science students, platforms help them understand other people's opinions. Students identified how networking helps them in learning how people think. In addition, SM enables them to connect with different communities and improves their open-mindedness. By being on SM, their boredom is reduced and the monotony resulting from daily routine is alleviated. On the downside, distraction and unproductivity are also identified as adverse effects of SM exposure (AlSharqi, Hashim \& Kutbi, 2015).

Networking media provide students with tools for performing many tasks. Group discussions, resource sharing, information access and entertainment are examples of the purposes that social networking serves. SM provides interactivity in learning outside the classroom. Shih (2011) focused on Web 2.0 as the platform for SM learning. Results showed that students can gain English proficiency through observing and commenting on their peers' posts on Facebook. The study's findings support the social constructivist theory of learning in which students acquire knowledge through their experiences interacting with their peers.

Al Samadani and Ibnian (2015) claimed that interactions between students over SM platforms have positive and negative implications. Furthermore, the researchers argued that the effects of SM on students are persistent in the short and long terms. Most SM platforms also use English as the first language. Such language is still necessary for those who have been customised (AbuSa'aleek, 2015). Therefore, as a first learning step, these networks enable students to learn basic English terminologies that are used in SM.

Recently, social perspectives on learning have increasingly inspired related research. Constructivist and social learning theories have inspired several studies on online learning (Shih, 2011). Since the 1990s, constructivism has had a strong influence on education, particularly in the field of instructional technology. Vygotsky (1978) developed social constructivist theory to emphasise the importance of social interaction in learning. Vygotsky (1978) argued that the distinction between constructivism and social constructivism is that, in social constructivism, learners are incorporated into a knowledge community based on language and culture. Learning is thus a collaborative process. Meanwhile, social constructivism assumes that students act within a social environment which is then followed by reflecting, abstracting and increasing experiential knowledge. The constructivism is learner-centred and students are actively engaged in knowledge construction rather than being just passive listeners. Within the principles of constructivist learning theory, meaningful interactions in a learning environment are designed to enhance meaning, including sharing various perspectives and experiences in communities of practice (Kamnoetsin, 2014). With the rapid development of SM and other technological tools, the ideal iteration of the constructivist-learning paradigm is how to use new media to enhance learning. SM is the tool that provides remote social interactions among individuals. This notion is consistent with the principles of social constructivism and explains why constructivist theorists focus on this powerful tool in their studies. Constructivism theory, in this sense, demonstrated how SM offers opportunities for students to interact online and obtain knowledge through many different sources. Therefore, constructivism concepts blend perfectly with technological affordances provided by SM.

The number of research offering valuable insights into the status of SNSs among university students has grown in recent years. However, the potential of this tool to positively affect students' attitudes has yet to be fully investigated. 
Therefore, the present study focuses on gaining a deep understanding of the perceptions and attitudes of Najran University students towards English and how the SM use can affect these attitudes. The study also aims to understand SM and how it can contribute towards learning foreign languages and recognising Saudi Arabian learners' perceptions of the role of online communication in improving their English language proficiency in the present era.

\section{MethodOLOGY}

\section{A. Data Collection Procedure}

Data are collected through surveys and semi-structured interviews. Thus, in the present study, the mixed method design was selected to investigate the research questions deliberately from different perspectives.

\section{B. Research Sampling and Participants}

Approximately 100 participants were expected to complete the survey. However, the results exceeded expectation, and a total of 228 (153 female, 75 male) students participated in the survey. Depending on the 'Rule of 100' by Gorsuch (1983) and Kline (1979), which recommends that no sample should be less than 100, the sample population of this research consisted of 228 young adults. Thus, this sample size was sufficient to obtain accurate and reliable results. The participants consisted of male and female undergraduate students enrolled in the Department of English, College of Languages at Najran University in Saudi Arabia. The level of English language and experience in learning among this sample could shed light on the usage of English language in various SNSs. These students could express their beliefs on how SM can facilitate English language learning and improve certain skills. The research participants were university students, with ages ranging from 18 to 24 . Thus, this group can be considered a group of young adults or late adolescents.

\section{Research Instruments}

A comprehensive questionnaire was used as the survey instrument. This instrument was designed for the current research, bearing its purpose, nature and objective to inform the participants about its scope. The questionnaire itself is based on a five-point Likert-scale, a unique parameter among social research methodologies in which participants can respond in terms of the degree of their agreeableness with question statements ranging from strongly disagree to strongly agree. Furthermore, enlisting the responses on Likert points equips researchers with a great leverage to categorise, objectify and analyse responses independently.

The survey tool also carried a communique for the respondents, outlining and reiterating the voluntary nature of their participation in the study and their extent of contribution for data collection. The questionnaire allows for a quick data gathering process from the large sample size consisting of students. The question items were specifically arranged to elicit genuine and systemic responses from the participants. The questionnaire contained prudently crafted statements, through which participants can document their individual responses and return the filled questionnaire through the same method in which it was handed to them initially. The study primarily used a mixed approach and-through logically arranged question items - followed a defined pattern to ascertain the participants' responses about the influence of SNSs on their attitudes towards EFL. The question items were prepared to assess the views of participants on the usage of SM platforms as a learning tool for English language. The questionnaire consisted of four parts. In the first cluster, participants responded to general questions relating to gender, GPA and the strength of association with SM, in addition to their primary purposes for its usage. The second cluster focused on SM platforms and how their usage influenced their understanding of the English language. The third cluster of questions addressed the effect of SM on learners' language proficiency, and the fourth cluster concentrated on the respondents' perspectives on how SM usage influenced their attitudes towards EFL.

\section{Research Procedure}

The research design included surveys and semi-structured interviews about SM usage and its effect on students' attitudes. Data were collected separately to analyse two datasets afterwards. Depending on the description of different types of comparison between qualitative and quantitative data, equal priority was given to both data sets in this research. However, the students took part in a survey first. Given the rapid expansion of SM, distributing the questionnaire online to the group of respondents to collect required data was appropriate. Prior to administering the survey questionnaire, clear and concise instructions were provided to the respondents, and they were made thoroughly aware about the nature of the study. Online platforms, including emails and survey websites like Google forms, were useful tools for creating and then distributing the questionnaire among students.

The survey was distributed to 20 participants as a part of the pilot study. The beginning and ending time was recorded to estimate the approximate time for completing the questionnaire. They took about 10 minutes to answer the whole survey. The reliability coefficient of the questionnaire was calculated using Cronbach's alpha. The value of .91 indicates that the internal consistency of the questionnaire's items is very high.

In order to simplify the data collection process, the improvised questionnaire was created online using Google forms. Thereafter, the students included in this study were kindly requested to submit their email addresses if they were willing to participate in a post-interview. As part of the research design, the interviews were deliberately selected to obtain 
students' perceptions towards EFL. Thus, the semi-structured individual interviews were conducted only with those who sent e-mails indicating their willingness to participate. The researcher contacted the 27 students who agreed and sent e-mails, but only 19 participants had time for the interview.

\section{RESUlts}

Descriptive and inferential statistics using SPSS were performed to find answers to the research questions stated in section 1.2. Means, standard deviations, skewness and kurtosis were run to determine the impact of SNSs on understanding and improving proficiency based on students' perceptions. An effect size t-test was computed to discover whether statistical differences exist among students' attitudes towards SNS usage, which can be attributed to gender and GPA. All values of statistical significance were calculated at .05. Cronbach's alpha was utilized to measure the level of reliability of the research tool used (i.e. questionnaire).

\section{A. Questionnaire Analysis}

\section{Reliability}

The reliability coefficient of the questionnaire was calculated using Cronbach's alpha. The Cronbach's alpha for the total items was .91, indicating very high internal consistency of the questionnaire's items. The excellent values of the total items of the questionnaire and the value for each item indicated the strong internal consistency of the items.

To know how students perceive their improvement in understanding English through SM usage, descriptive statistics were run to elicit the means and standard deviations of their responses on the questionnaire items. The results are summarised in Table 1.

TABLE I

DESCRIPTIVE STATISTICS FOR STUDENTS’ IMPRESSIONS ABOUT UNDERSTANDING ENGLISH SM USAGE $(\mathrm{N}=228)$

\begin{tabular}{|c|c|c|c|c|c|}
\hline No. & Item & M & SD & Skewness & Kurtosis \\
\hline 1 & I think SM is a good platform to learn English from. & 4.19 & 1.07 & -1.47 & 1.74 \\
\hline 2 & I see that SM improves my language skills. & 4.1 & 1.04 & -1.5 & 2.38 \\
\hline 3 & I do not think SM offers any benefit to my language. & 1.76 & .96 & 1.64 & 2.61 \\
\hline 4 & $\begin{array}{l}\text { SM usage helps me reduce my first language use when communicating with } \\
\text { friends and classmates. }\end{array}$ & 2.6 & 1.26 & .30 & -.89 \\
\hline \multirow[t]{3}{*}{5} & I enjoy using SM for learning English. & 3.98 & 1.06 & -1.13 & .93 \\
\hline & Total means & 3.3 & .64 & -.71 & 2.10 \\
\hline & Total means excluding negative Item (3) & 3.73 & .82 & -.92 & 1.09 \\
\hline
\end{tabular}

Table 1 reveals that the overall means of all items is 3.3, indicating that students perceive the positive effects of SM usage on their understanding of English. Such perception value can be interpreted as high. Excluding the negative Item (3), the total

Kline (2005) claimed that when skewness indices are valued between $+/-2$ and kurtosis is within a range of $+/-3$, data can be assumed as normally distributed. Therefore, data in our study can be considered as normally distributed. Moreover, Item (1) has the highest mean $(M=4.19, S D=1.07)$, indicating that the participants believed that $\mathrm{SM}$ is a good platform upon which they can learn. Item (3) had the lowest mean $(M=1.76, S D=.96)$, showing that the responses on the statement that SNSs do not offer any benefit to their language is very low. Therefore, students feel that they benefited from SM usage.

TABLE II.

\begin{tabular}{|c|c|c|c|c|c|}
\hline No. & Item & $\mathrm{M}$ & $\mathrm{SD}$ & Skewness & Kurtosis \\
\hline 1 & $\begin{array}{l}\text { I think SM usage helps in understanding English acronyms. (e.g. LOL [laughing out } \\
\text { loud], OMG (oh my god). }\end{array}$ & 4.3 & 1.0 & -1.6 & 2.3 \\
\hline 2 & SM usage helps improve my spelling skills in English. & 4.0 & 1.05 & -1.0 & .61 \\
\hline 3 & $\begin{array}{l}\text { SM usage contributes towards my ability to summarise and shorten statements in } \\
\text { English. }\end{array}$ & 3.8 & 1.16 & -.77 & -.32 \\
\hline 4 & SM improves my skills in reducing repetition errors. & 3.7 & 1.1 & -.54 & -.70 \\
\hline 5 & $\begin{array}{l}\text { I have learned English jargons through SM. (e.g. texting [typing a message], googling } \\
\text { [searching the Internet], tweeting [posting a tweet on Twitter]. }\end{array}$ & 4.2 & 1.05 & -1.5 & 1.99 \\
\hline \multirow[t]{2}{*}{6} & SM has contributed towards my pronunciation of English words. & 4.2 & 1.0 & -1.4 & 1.8 \\
\hline & Total means & 4.0 & .84 & -.96 & .79 \\
\hline
\end{tabular}

As seen in Table 2, the skewness and kurtosis values reveal normally distributed data. The total means of students' responses towards the impact of SM on their English proficiency is 4.0, indicating that their perceptions are high. Item (1) depicts the highest response of the participants, showing that they perceive that SNS usage helps them in understanding English acronyms. Their perceptions improved $(M=4.3, S D=1.0)$, which indicates very high perceptions. However, the lowest responses $(M=3.7, S D=1.1)$ come from the participants who believe that SM can improve their skills in reducing repetition errors. Yet, their response is still high.

Means and standard deviations were utilised to obtain their scores on responses. Skewness and kurtosis were also run 
to see the normal distribution of data. Results are summarised in Table 3.

TABLE III.

DESCRIPTIVE STATISTICS OF STUDENTS' ATTITUDES TOWARDS LEARNING ENGLISH $(\mathrm{N}=228)$

\begin{tabular}{|c|c|c|c|c|c|}
\hline No & Item & $\mathrm{M}$ & SD & Skewness & Kurtosis \\
\hline 1. & SM usage helps me in studying English because it makes me more educated. & 3.93 & 108 & -.97 & .32 \\
\hline 2. & I feel proud when using English on SM. & 4.16 & 1.10 & -1.33 & 1.00 \\
\hline 3. & I feel excited when communicating with others on SM using English. & 4.26 & 1.02 & -1.55 & 2.14 \\
\hline 4. & I feel worried when using English on SM groups due to criticism from others. & 2.32 & 1.24 & .60 & -.73 \\
\hline 5. & I like sharing my opinions in English on SM. & 3.21 & 1.36 & -.11 & -1.21 \\
\hline 6. & I feel I gain knowledge and understanding of English grammar when using SM. & 3.60 & 1.25 & -.53 & -.74 \\
\hline 7. & I do not get anxious when required to respond in English on SM. & 3.59 & 1.25 & -.57 & -.69 \\
\hline 8. & When I hear a friend speak English well, I like responding for good practice. & 4.14 & 1.09 & -1.43 & 1.50 \\
\hline 9. & Using English on SM helps me create good emotions (feelings). & 3.78 & 1.14 & -.66 & -.37 \\
\hline 10. & $\begin{array}{l}\text { When I have a chance to communicate with others in my first language, I prefer } \\
\text { using it as opposed to English. }\end{array}$ & 3.31 & 1.28 & -.21 & -1.06 \\
\hline 11. & I put off communication on SM using English as much as possible. & 2.14 & 1.19 & .90 & -.08 \\
\hline 12. & Using English on SM increases my confidence on the use of the language. & 4.04 & 1.09 & -1.11 & .61 \\
\hline 13. & SM helps me pay attention to the quality of English. & 3.94 & 1.13 & -1.02 & .40 \\
\hline 14. & SM enhances motivation to communicate using English. & 4.00 & 1.14 & -1.08 & .41 \\
\hline 15. & SM enhances positive attitudes to English language learning & 4.03 & 1.08 & -1.16 & .91 \\
\hline & Total Means & 3.63 & .68 & -1.00 & 1.72 \\
\hline & Total means if negative items are excluded (Items [3], [11]) & 3.7 & .72 & -.9 & 1.2 \\
\hline
\end{tabular}

Table 3 shows that the total means reach 3.6, indicating that these students' overall attitudes towards the contribution of SNSs in learning English are high. The highest item that received significant response is Item $(3)(M=4.2, S D=1.0)$, concerning the feeling of excitement when communicating with others on SM using English. However, Item (11) gained a low scores $(M=2.14, S D=1.1)$, revealing that such students' withdrawal from communication in English with others is low. Therefore, these students feel confident when communicating with others in English using SM.

An inferential statistics (t-test) was run to see how male and female students perceive learning English via SM. However, we did not have an equal number of participants across the gender factor (i.e. male $=75$, female $=153$ ). Thus, a non-parametric (Mann-Whitney) test was used to control the variation of the sample size. Table 4 presents the results of the non-parametric test.

TABLE IV.

MANN-WHITNEY TEST FOR STUDENTS ATTITUDES TOWARDS SNSS AND LEARNING ENGLISH

\begin{tabular}{clllll}
\hline Mann-Whitney test & & & & \\
\hline \multirow{3}{*}{ Students' attitudes } & Gender & N & Mean Rank & Sum of Ranks \\
& Female & 153 & 117.58 & 17989.00 & 8117.00 \\
& Male & 75 & 108.23 & \\
& Total & 228 & & .31 \\
\hline
\end{tabular}

The Mann-Whitney test indicated no significant differences in the attitudes of female $(M d n=3.7)$ and male $(M d n=$ 3.6) students, $U=117.5, p=.31, r=.15$

A one-way ANOVA was used. However, we did not have equal number of participants across the GPA factor. Thus, a non-parametric (Kruscal-Wallis) test was used to control the variation of the sample size. Table 5 reports the results of the non-parametric test.

The Kruscal-Wallis test indicated no significant differences in the attitudes of the participants based on their GPA, $F$ $(4,223)=2.79, p=$. 027. However, the post-hoc analysis shows that statistically significant differences exist between the students whose GPA ranged between 3-4 $(M=3.68, S D=.53)$ over those whose GPA ranged between $1-2(M=$ $3.1, S D=.81) p=.048$. No significant differences are found among other GPA rates.

TABLE V

RESULTS OF THE NON-PARAMETRIC TEST

\begin{tabular}{cllllll}
\hline & & & \multicolumn{2}{c}{ Kruscal-Wallis Test } \\
\hline GPA & $\mathrm{N}$ & Mean & SD & Mean Rank & Sig \\
& $1-2$ & 14 & 3.10 & .81 & 71.29 & .027 \\
$2-3$ & 57 & 3.48 & .71 & 107.23 & \\
Students' Attitudes & $3-4$ & 83 & 3.68 & .53 & 123.73 & \\
& $4-4.5$ & 35 & 3.60 & .70 & 123.53 & \\
& $4.5-5$ & 39 & 3.59 & .60 & 112.88 & \\
Total & 228 & 3.57 & .65 & 71.29 & \\
\hline
\end{tabular}

\section{B. Interview Analysis}

According to the Arab Social Media Report (2011), the growth of SM in the region and the shift in usage trends have played critical roles in the mobilisation, empowerment, shaping of opinions and influential changes that occurred in recent years. However, many traditional institutions teaching EFL continue to restrict and limit interactions and 
collaborations within classes. Thus, most EFL students have adopted the use of SM as their learning and practice platforms (Razak, Saeed \& Ahmad, 2013). Having administered the questionnaire, 19 students were interviewed to obtain their opinions, feelings and attitudes about SM usage during their learning process. The responses of 19 participants were qualitatively analysed using a constant comparative method, in order to develop a grounded theory based on the research questions (Zhang \& Wildemuth, 2009).

RQ1: How does SM improve the understanding of English from the perspective of EFL learners?

According to the interview analysis, SM improves the understanding of most students through the introduction of new vocabulary, which assists them in real-life communication. Students stated that SM is equipped with many words, and through their interaction, they are able to add new words to the lists of words they have learnt. As one student shared, 'It enhances my vocabulary and no day passes without learning at least one new word' (Participant 7).

The interviewed students asserted that SM platforms provide them with exposure through which they can practice through writing, viewing photos, watching videos and following influential people who assist them in learning. Another student said, 'I learn many words and vocabularies from videos and photos I see on Instagram and Twitter' (Participant 5). In this category, students stated that SM exposes them to different cultures in different countries where they can learn different accents of the language; hence, their understanding is also improved in the process. Moreover, these students expressed that SM not only helps them with practicing but that it also plays a critical role in illustrating contextual meanings of various words and phrases they encountered. One student shared that SM enhances collaborative learning, which improves the understanding of certain words and phrases which are easy to remember.

RQ2: How does SM impact English proficiency from the perspective of EFL learners?

The responses can be classified into two main categories. The first division (majority) comprises those who believe that SM positively affects English proficiency by improving their writing, listening, reading and speaking skills. The respondents think that SM encourages active participation and offers different materials that they can use to practice. For example, one of the students said, 'Social media help me learn slang language, which I cannot learn from regular classes' (Participant 3). Participant 3 argued that the language learnt in class is not typically used among people in daily life. Thus, SM, especially Snapchat and Twitter, enables her to communicate with others effectively and more naturally in daily life.

The second category comprises responses from students who maintain that SM improves their English proficiency by improving their vocabulary. They argue that SM is rich in English-related materials, such as idioms, jargons and phrases among others, which improve their proficiency. They believe that the availability of these English-related materials at their disposal has enabled them to practice and apply in chats, thereby improving their proficiency.

RQ3: How does SM usage influence the attitudes of EFL learners towards English?

All interviewed EFL students $(N=19)$ cited that SM usage results in positive attitudes towards English. However, they pointed out different factors that lead to their ultimate eagerness to learn English. Most of them $(N=16)$ stated that SM usage makes them confident and comfortable, thus motivating them to learn. They also maintained that SM offers a platform for the correction of spelling words and mistakes in text usage in case of a wrong context, thus further developing their perception of English.

As one student asserted, "Social media is the main reason why I have decided to study English." She said, "Most of the communication on social media have been created in English, and in most times, I could not figure out what the messages mean and found myself lost in a world speaking a language that I could not comprehend. That's why I decided to specialise in the English language" (Participant 6). Therefore, the rest of the students $(N=13)$ were asked if their specialisation in English was affected by SM usage. All of them agree that that SM does in one way or another.

One of the students asserted that although SM has an undeniable positive effect on her attitude, she sometimes develops a slightly negative attitude when she sees people using inappropriate language or posting abusive content online. However, when she sees people with a pretty good accent and using appropriate language, she is encouraged and motivated to learn English.

Based on the results of the interviews, SM evidently plays a critical role in improving the EFL learners' understanding, proficiency and attitudes. Therefore, institutions that offer specializations in an EFL course must integrate and incorporate SM in their programmes to facade effective and efficient learning.

\section{DISCUSSION OF THE FINDINGS}

\section{A. SM Improvement of Students' Understanding of English}

In the first research question, the participants were required to state their level of agreement from very low to very high for 5 items in the questionnaire: 'I think SM is a good platform to learn English from', 'I see that SM improves my language skills', I do not think SM offers any benefit to my language', 'SM usage helps me reduce my first language use when communicating with friends and classmates' and 'I enjoy using SM for learning English. Table 1 shows that the participants in this study have an overall positive attitude towards the influences of SM on their understanding of English. Such a result is consistent with the research findings of Wang et al. (2012), who concluded that the continuing medical education course participants have positive attitudes towards using SM for educational purposes. Moreover, whilst the total means (excluding Item [3] because it is negative) is high with the value of 3.73, the total mean is moderate with the value of 3.3. Still, both values fall in the categories of moderate (from 2.61 to 3.40 ) to high (from 
3.41 to 4.20) corresponding levels. Hence, the result is consistent with Vygotsky's (1978) social constructivism theory, which assumes that students act within a social environment which is then followed by reflecting, abstracting and increasing experiential knowledge. Moreover, the communication between the learners and other people in SM as an important factor in language learning is the interaction in the target language (Miangah \& Nezarat, 2012).

The corresponding levels of participants in RQ1 vary from 1.76 to 4.19, which indicates the positive influences of $\mathrm{SM}$ on learners' understanding of English. Table 1 shows that Items (1), (2) and (5) have high ratings with means $\mathrm{M}=$ 4.19, 4.1 and 3.98,, whereas items (3) and (4) have low ratings with means $M=1.76$ and 2.6, respectively. Hence, the result is consistent with the study by Goel and Singh (2016), who found that encouraging SM as a tool for information sharing can help to improve academic performance in management department and even student performance in diverse academic areas. Item (1) has the highest mean of 4.19 (SD = 1.07), indicating that students at Najran University believe that SM is a good platform for learning English. Similarly, Item (2) has a mean value of $4.1(\mathrm{SD}=1.04)$, indicating that students realise the improvement in their language skills through SM. Such a result supports the findings of Swan and Shea (2005), who concluded that students perceive themselves as interacting socially using SM and that this social interaction is meaningful to their learning.

Moreover, students also enjoy using SM for learning English. This result is reflected in item (5) with a rendered mean value of 3.98 ( $\mathrm{SD}=1.06$ ). Item (5) also indicates the positive feelings of those students towards learning English through SM. Such a result is consistent with the findings of Al-Sharqi, Hashim and Kutbi (2015), who concluded that SM reduces boredom as it alleviates the monotony resulting from daily routines. This also supports the findings of Dizon (2015), who stated that participants express enthusiasm for SM usage in language learning with some positive benefits cited by students in the study population, including ease of use, low stress levels and convenience.

Item (3) (I do not think SM offers any benefit to my language) has the lowest rendered mean $1.76(\mathrm{SD}=0.96)$. However, Items (2) and (3) contradict each other. The result perfectly demonstrates that SM positively influences the understanding of English from the perspective of EFL learners. This statement is consistent with that of Al-Sharqi et al. (2015) that most communication on social networks are developed in English. As students figure out what the messages mean, their level of English language comprehension is also improved in the process. Therefore, the overall perspectives of students change when they realise that they are making progress in the process of English language learning. Accordingly, whilst most students recognise that SM platforms improve their language skills, only a few of them think otherwise.

\section{B. SM Impact on English Proficiency of the Learners}

The participants responded to the second research question by stating their level of agreement for 6 items in the questionnaire: 'I think SM usage helps in understanding English acronyms', 'I have learned English jargons through SM', 'SM usage helps improve my spelling in English', 'SM usage contributes towards my ability to summarise and shorten statements in English', 'SM usage improves my skills in reducing repetition errors', 'SM platforms have contributed towards my pronunciation.' Table 2 presents the descriptive statistics of the items. It shows high positive attitudes towards the influences of SM on English proficiency from the perspective of EFL learners. Thus, the result is consistent with the findings of Shih (2011), who argued that students can gain English language proficiency by observing and commenting on their peers' posts on Facebook. Whilst the total mean is rendered with the value of 4.0, the 6 items' values fell in the category from high (from 3.41 to 4.2) to very high (from 4.21 to 5.0) corresponding levels. This result reflects the principle of constructivist learning theory, which states that meaningful interactions in a learning environment, including sharing various perspectives and experiences in communities of practice, are designed to enhance meaning (Kamnoetsin, 2014).

The corresponding levels of the participants in RQ2 vary from 3.7 to 4.3 , indicating totally positive attitudes by such students. The highest mean value of Item (1) 4.3 (SD = 1.0) and (5) 4.2 (SD = 1.05) indicates that students believe SM usage helps in their understanding of English acronyms and jargons. The rampant use of the slang language by people on SM can justify this statement. Most people minimise their conversations using tiny keys to speed up their conversation. Hence, students learn these acronyms and jargons by being exposed to SM. This result supports the statement of AbuSa'aleek (2015) that most SNSs use English as the first language and even for those that have been customised, English knowledge is necessary. Therefore, as a first learning step, these networks enable students to learn basic English terminologies that are commonly used on SM.

In addition, item (6) with a high mean value of $4.2(\mathrm{SD}=1.0)$ indicates that students believe that $\mathrm{SM}$ contributes towards their pronunciation. Thus, the result supports the research of González (2017) on the pronunciation instruction through Twitter, in which they investigated the potential of a Twitter-based approach based on explicit instruction to help EFL learners improve their pronunciation. Results revealed that this approach induces significant improvements in learners' pronunciation of the target features and that such improvements are maintained over time. Moreover, the research of Akbari, Naderi, Aliabadi, Simons and Pilot (2016) showed that the mindset of students towards foreign dialects before exposure to SM is different from their perspective after attending some classes. Thus, they concluded that social networks are useful tools for learning foreign dialects. The result also supports the study of Miangah and Nezarat (2012), who concluded that the speech aspect of mobile learning is as significant as its textual aspect as it enables learners to comfortably speak with a system that records their voice and allows them to listen back to themselves. Through this process, they can compare their voice with an ideal pronunciation and work on this skill. 
Similarly, Item (2) with a mean value of 4.0 (SD 1.05) reflects that the students believe SM usage helps improve their spelling in English. This finding is inconsistent with that of Cowins (2017), who stated that in this technological age of computers and SM, spelling may become extinct given that people are becoming progressively unconcerned with their ability to spell with the autocorrect, shorthand and shortcut functions in most gadgets and apps.

Item 3 with a mean value of 3.8 (SD 1.16) indicates that those students believe SM usage contributes towards their ability to summarise and shorten statements in English. For example, Twitter users only have 280 characters to express themselves per tweet. Thus, they learn how to summarise their ideas in a short meaningful sentence.

In general, the perception of the students of this reserach about the influences of SM on their English proficiency is positive. Such a perception supports the notion that these tools form the basis of the current evolution of the Internet and are based on the premise that individuals derive their competence through the connections they make (Dogoriti, et.al 2014; Siemens, 2004).

\section{The Influence SM Usage on the Attitudes of the Learners towards English}

The participants of this study were required to state their level of agreement with 15 items in the questionnaire. Table 3 presents the descriptive statistics of these items. It shows a positive attitude towards the influences of SM usage and the attitudes of EFL learners towards English (the third key DV). The total mean (excluding Items [4] and [11] because they are negative) is high with the value of 3.7, whereas the total mean is 3.63. Still, both values fall in the category of high corresponding levels (from 3.41 to 4.20).

Results indicated that the students believe SM usage helps them study English because it makes them educated (Item [1], $\mathrm{M}=3.93, \mathrm{SD}=1.08$ ), feel proud when using English on SM (Item [2], $\mathrm{M}=4.16, \mathrm{SD}=1.10$ ), feel excited when they are communicating with others on SM using English (Item [3], M = 4.26, SD = 1.02). Students love having their voice heard, and the Internet opens their products to a worldwide audience. Networking sites allow connection to a large community as users with similar interests serve as an authentic audience (Purcell, 2012).

They also believed that using English whilst on SM helps them create good emotions (feelings) (Item [9], M = 3.78, $\mathrm{SD}=1.14)$, which is consistent with the finding of Omar et al. (2012) that many respondents feel that Facebook allows them to have free and comfortable communication with their group members, especially those who are shy and lack confidence to initiate face-to-face interactions. They believe that using English on SM increases their confidence in using the language (Item [12], $\mathrm{M}=4.04, \mathrm{SD}=1.09$ ). This result is supported by the research findings of AbuSa'aleek (2015), who stated that the confidence and motivation of students towards acquiring English speaking skills improves after using Facebook as a learning tool.

The students also do not get anxious when required to respond in English on SM (Item [7], M = 3.59, SD = 1.25). This finding is consistent with that of the study of Lin et al. (2014), who concluded that students who use SM to do their homework experience considerably less anxiety than the control group who uses a traditional method of learning.

Moreover, the participants believed that SM motivates communication using English (Item [14], M = 4.00, SD = 1.14). This result is in line with the findings of Al-Sharqi et al. (2015) and Akbari et al. (2014), who found that these platforms can create new opportunities and contexts in which students can increase their motivation for learning. It also supports the research findings that the confidence and motivation of students towards acquiring English speaking skills are improved after using Facebook as a learning tool (AbuSa'aleek, 2015).

Finally, they believe that SM enhances positive attitudes towards EFL learning (Item [15], M = 4.03, SD = 1.08). This result is consistent with Lin et al.'s (2014) research finding that using blogs positively affects the learners' perceptions and attitudes towards learning a second language.

Item (4) with a low mean value of $2.32(\mathrm{SD}=1.24)$ indicates that such students do not feel worried when using English on SM groups due to criticism from others. Moreover, Item (11) with a mean value of $2.14(\mathrm{SD}=1.19)$ specifies that most students do not avoid communication on SM using English as much as possible. Although Items (4) and (11) imply negative attitudes, students' responses reflect low ratings on both items, indicating that students' attitudes towards using English on SM is not negative. Such a result is consistent with the study of Al Samadani and Ibnian (2015) on the attitudes of university students towards learning EFL. They identified the factors that affect students' attitudes towards EFL learning, and one of them is the nature of communication and interaction through social networks.

\section{Gender and GPA on the Attitudes of the Participants towards Learning English through SM}

In terms of the student's gender factor, the result from the Mann-Whitney test indicated that there are no significant differences in the attitudes of the female $(\mathrm{Mdn}=3.7)$ over male $(\mathrm{Mdn}=3.6)$ students, $\mathrm{U}=117.5, \mathrm{p}=.31, \mathrm{r}=.15$ (Table 4). Based on the results of this study, gender does not influence either the attitudes of students using SM for learning English nor their academic performance. Therefore, this result supports the findings of Aifan (2015), who concluded that there is no statistically significant difference between Saudi male and female students in their attitudes toward using SM to support learning.

Talking about GPA, the results from the non-parametric (Kruskal-Wallis) test indicate that there are no significant differences in the attitudes of the participants in terms of their GPA: F $(4,223), p=.027$. However, the post-hoc analysis showed statistically significant differences between students whose GPAs range from 3-4 $(\mathrm{M}=3.68, \mathrm{SD}=.53)$ over those whose GPAs range from $1-2(\mathrm{M}=3.1, \mathrm{SD}=.81) \mathrm{p}=.048$ (Table 5). Whilst the GPA factor does not significantly 
influence the attitudes of the group with GPAs ranging from 3-4, it influences the attitudes of those with GPAs ranging from 1-2. Thus, the result partly supports the findings of Al-Samadani and Ibnian (2015), who studied the link between students' attitudes and their academic performance through their GPAs. Concerning the relation between attitudes towards EFL and academic performance, the researchers found that students with a positive viewpoint towards learning EFL have better performances than those with negative perspectives (Al-Samadani \& Ibnian, 2015). In short, whilst no statistically significant difference can be attributed to the participants' gender in their attitudes of the participants towards learning English through SM, the GPA factor influences the attitudes of the student group with low GPA differently compared with other student groups with higher GPA.

\section{CONCLUSION}

In summary, the results of the first research question revealed, from their perspectives, they thought that the use of SM positively improved their understanding of English. They also believed that the SM served as a good platform for learning English and improving their language skills. This finding is consistent with that of Gumport and Chun (1999), who asserted that the purpose of integrating technology in education is to improve the standard of teaching and learning.

For the second research question, from their perspectives, the students highly believed that SM positively affected their English proficiency. Similarly, the students believed that the use of SM helped in their understanding of English acronyms and jargon. Accordingly, the online interactions of Saudi students with other individuals helped them update their usage of informal and common acronyms, which are not formally taught in an academic environment. In addition, the students also believed that SM contributed towards their pronunciation of English words. The online interactions via audio and voice chat also helped them sharpen their pronunciation through conversations with various ranges of English accents. Moreover, they highly believed that the use of SM improved their spelling skills in English. In addition, SM positively influenced their English proficiency because students were given daily opportunities to practice their language with others. Hence, it can be concluded that the employment of SM for online interaction and educational purposes influences the communication styles and the writing skills of the participants. Whilst SM may provide positive development in language teaching, it is necessary to consider the framework by which this tool can cross the line between the positive and negative influences in teaching and learning English using SM.

For the third research question, the students highly believed that the SM usage positively influenced their attitudes towards English. The students acquired certain levels of positive emotions when they employed SM for learning English, including the feeling of being more educated, excitement in English communication, increasing their confidence in using the language and feeling less anxious when they are required to respond in English. Additionally, SM usage enhanced their positive attitudes toward English language learning. Thus, the high awareness of students proves that they have an overall positive attitude towards learning English through SM.

Finally, the results demonstrate that there is no statistically significant difference that can be attributed to gender in the attitudes of the participants towards learning English through SM. This conclusion is constructed from the results on the attitudes of female students over the male ones. However, as there were more female than male participants, this result may be biased. Furthermore, there is a statistically significant difference between students with GPAs ranging from 1-2 and from 3-4. The conclusion is based on the means values of students, whose GPAs ranged between 3-4 over those, whose GPA ranged between 1-2. Hence, it can be concluded that the positive attitudes of students would decide the range of their GPA in studying English. Although there was no statistically significant difference within other ranges of GPA, the GPA factor does not have much influence on their attitudes towards learning English through SM.

In conclusion, this study has proven that students' knowledge, attitudes and learning attainment are positively affected by their usage of SM. This finding may be considered useful by policy makers and teachers in increasing the development and employment of technological integration in classrooms. SM platforms have great educational potential and teachers can use many ways to integrate SM to their full advantage. One of these ways is to ask the students to create a group on WhatsApp or Telegram and invite all the students to join. Then, the teacher can start discussion topics and the students who participate will get marks for that. Another example is to organise an active Twitter discussion thread and ask students to post a tweet with an interesting fact about the topic of discussion. This could motivate students to research, summarise their ideas and then express them in meaningful sentences. Indeed, teachers can employ numerous SM platforms in the learning process to encourage students to learn English. However, these platforms can act as distractors if improperly used. Teachers should thus notify students to follow rules that guarantee the effective use of technology, and then ask the students to sign a pledge to follow these rules. In conclusion, teachers should be aware that it is time to leave the old style of teaching and reconsider their adherence to traditional methods in favour of newer teaching strategies for the benefit of their students.

\section{REFERENCES}

[1] AbuSa'aleek, A. O. (2015). Students' perceptions of English language learning in the Facebook context. Teaching English with Technology, 15(4), 60-75.

[2] Aifan, H.A. (2015). Saudi students' attitudes towards using social media to support learning (Doctoral dissertation). Retrieved from https://kuscholarworks.ku.edu/bitstream/handle/1808/19498/Aifan_ku_0099D_13943_DATA_1.pdf;sequence=1 
(retrieved on 12/1/2018).

[3] Akbari, E., Eghtesad, S., \& Simons, R. (2014). Students' attitudes towards the use of social networks for learning the English $\begin{array}{lllll}\text { language. } & \text { ICT } & \text { for } & \text { Language } & \text { Retrieved }\end{array}$ http://conference.pixelonline.net/ICT4LL2012/common/download/Paper_pdf/357-IBT70-FP-Akbari-ICT2012.pdf(retrieved on 2/3/2019).

[4] Akbari, E., Naderi, A., Simons, R. J., \& Pilot, A. (2016). Student engagement and foreign language learning through online social networks. Asian-Pacific Journal of Second and Foreign Language Education, 1(1), 1-22.

[5] Al Samadani, H. A., \& and Ibnian, S. S. (2015). The relationship between Saudi EFL students' attitudes towards learning English and their academic achievement. International Journal of Education and Science, 2(1), 92-102.

[6] Allam, M., \& Elyas, T. (2016). Perceptions of using social media as an ELT tool among EFL teachers within the Saudi context. English Language Teaching, 9(7), 1-9.

[7] Alm, A. (2006). CALL for autonomy, competency, and relatedness: Motivating language learning environments in Web 2.0. The JALT CALL Journal, 2(3), 1-10

[8] Al-Sharqi, L., Hashim, K., \& Kutbi, I. (2015). Perceptions of social media impact on students' social behavior. International Journal of Education and Science, 2(4), 122-131.

[9] Arab Social Media Report. (2011). The Impact of Facebook and Twitter. [Online] 1(2), 3-7. Available At: Http://Unpan1.Un.Org/Intradoc/Groups/Public/Documents/Dsg/Unpan050860.Pdf [Accessed 17 Apr. 2018].

[10] Bahrani, T. (2011). Speaking fluency: Technology in EFL context or social interaction in ESL context. Studies in Literature and Language, 2, (2), 162-168.

[11] Baird, D.E\& Fisher, M. (2005). Neomillennial user experience design strategies: utilizing social networking media to support "always on" learning styles. Journal of Education Technology System, 34(1).

[12] Cowins, S. (2017). Spelling and grammar in the age of social media. [Blog] Math Genie. Retrieved from https://www.mathgenie.com/Blog/spelling-grammar-social-media (retrieved on 22/1/2018).

[13] Dabbagh, N., \& Kitsantas, A. (2012). Personal Learning Environments, social media, and self-regulated learning: A natural formula for connecting formal and informal learning. The Internet and Higher Education, 15(1), 3-8.

[14] Dizon, G. (2015). Japanese Students' Attitudes towards the use of Facebook in the EFL Classroom. The Language Teacher, 39(5), 9-14.

[15] Dogoriti, E., Pange, J., \& Anderson, G. (2014) Use of social management systems in English language teaching in higher education. Campus-Wide Information systems, 31(4), 254-263.

[16] Donelan, H., Kear, K. \& Ramage, M. (2010). Online communication and collaboration: A reader. Abingdon: Routledge.

[17] Elsayed ,Hussein Ali. Islam. (2011). E learning 2.0: Using Blogs as powerful tool to enhance and support Higher Education applied to Braunschweig University. The Conference of Electronic Learning and Distant Education. Al-Riyadh.

[18] Fralinger,B.\& Owens, R. (2009). YouTube as a learning tool. Journal of College Teaching \& Learning, 6(8), 15-28.

[19] Goel, D., \& Singh, M. (2016). Impact of students attitudes towards S. M. use in education on their academic performance. AIMA Journal of Management \& Research, 10 (2-4).

[20] Gorsuch, R. L. (1983). Factor Analysis (2nd. Ed). Hillsdale, NJ: Lawrence Erlbaum Associates.

[21] Gumport, P. J., \& Chun, M. (1999). Technology and higher education: Opportunities and challenges for the new era. In P. G. Altbach, R. O. Berdahl \& P. J. Gumport (Eds.), American Education in the 21st Century (pp. 370-395). Baltimore, MD: Johns Hopkins University Press.

[22] Jonás Fouz-González (2017) Pronunciation instruction through Twitter: the case of commonly mispronounced words, Computer Assisted Language Learning, 30 (7),631-663, DOI:10.1080/09588221.2017.1340309 (retrieved on 24/8/2018).

[23] Kamnoetsin, T. (2014) "Social media use: A Critical analysis of Facebook's impact on collegiate EFL students' English writing in Thailand. Seton Hall University Dissertations and Theses (ETDs). Retrieved from www.scholarship.shu.edu/dissertations/2059 (retrieved on 5/2/2019).

[24] Kaplan, A. M., \&. Haenlein, M. (2010). Users of the world, unite! The challenges and opportunities of social media, Business Horizons, 53(1), 59 -68.

[25] Kline, P. (1979). Psychometrics and psychology. London: Acaderric Press.

[26] Kline, R. B. (2005). Principles and Practice of Structural Equation Modelling (2nd ed.). New York: Guilford Press.

[27] Lin, M. H., Li, J. J., Hung, P. Y., \& Huang, H. W. (2014). Blogging a journal: Changing students' writing skills and perceptions. ELT Journal, 68(4), 422-431.

[28] Miangah, T. M., \& Nezarat, A. (2012). Mobile-Assisted Language Learning. International Journal of Distributed and Parallel Systems (IJDPS), 3(1), 309-319.

[29] O'Reilly, T. (2005). What is web 2.0. Design patterns and business models for the next generation of software. from www.oreillynet.com/pub/a/oreilly/tim/news/2005/09/30/what-is-web- 20.html (retrieved on 10/4/2018).

[30] O'Reilly, T. (2007). What is web 2.0. Design patterns and business models for the next generation of software. Communications \& Strategies, 65, 17-37. Retrieved from http://mpra.ub.uni-muenchen.de/4578/ (retrieved on 17/1/2018).

[31] Omar, H., Embi, M. A., \& Yunus, M. (2012). ESL learners' interaction in an online discussion via Facebook. Asian Social Science, 8(11), 67-74.

[32] Prensky, M. (2006). Listen to the natives. (School should improve teaching). Educational Leadership, 63(4), 8-13.

[33] Purcell, M. A. (2012). The Networked Library. A Guide for the Educational Use of Social Networking Sites. California: Linworth.

[34] Razak, N. A., Saeed, M., \& Ahmad, Z. (2013). Adopting social networking sites as interactive communities among English foreign language (EFL) learners in writing: Opportunities and challenges. English Language Teaching, 6(11), 187-195

[35] Seo, K. (2013). Using Social Media Effectively in the Classroom: blogs, wikis, twitter, and more. Rutledge. New York and London.

[36] Shih, R. (2011). Can Web 2.0 technology assist college students in learning English writing? Integrating Facebook and peer assessment with blended learning. Australasian Journal of Educational Technology, 27(5), 829-845. 
[37] Siemens, G. (2004). Connectivism: A Learning Theory for the Digital Age. Retrieved from www.elearnspace.org/Articles/connectivism.htm (retrieved on 5/3/2017).

[38] Swan, K., \& Shea, P. (2005). The development of virtual learning communities. In S. R. Hiltz \& R. Goldman (Eds.), learning together online: Research on asynchronous learning networks (pp.239-260) New /York, NY: Hampton Press.

[39] Vygotsky, L. S. (1978). Mind in society: The development of higher psychological processes. Cambridge, MA: Harvard University Press.

[40] Wang, Amy T.; Sandhu, Nicole P.; Wittich, Christopher M.; Mandrekar, Jayawant N. ; and Beckman, Thomas J. (2012). Using Social Media to Improve Continuing Medical Education: A Survey of Course Participants. Mayo Clinic Proceedings.

[41] Yagci, T. (2014). Mobile social media challenges digital natives in EFL learning. Journal of Educational \& Instructional Studies in the World, 4 (4), 49-53.

[42] Zhang, Y., \& Wildemuth, B. M. (2009). Qualitative analysis of content. In B. Wildemuth, (Ed.), Applications of Social Research Methods to Questions in Information and Library Science, Libraries Unlimited, 308-319.

S. M. Fazlul Haque obtained his B.A. (Hons.) and M.A. in English from the University of Dhaka, Dhaka, Bangladesh in the years 1969 and 1970 respectively. He was awarded an M.A. and a PhD in Applied Linguistics by the University of Durham, United Kingdom in the years 1986 and 1989 respectively. He is currently a Professor in the Department of English at the College of Languages, Najran University, Saudi Arabia. Prior to his appointment at Najran University, he also served in the College of Languages and Translation at King Saud University in Riyadh, Saudi Arabia and in the Department of English at the University of Dhaka, Dhaka, Bangladesh. Besides classroom teaching, he has also been engaged in supervising postgraduate research students. He has got a number of publications to his credit published in different accredited journals.

Norah Mofareh Al-Salem got her M.A. in Applied Linguistics from the University of Najran, Saudi Arabia in 2018. She is now serving as a Lecturer in the Department of English at the College of Languages, Najran University, Saudi Arabia. 